\title{
LA APUESTA POR LA MEJORA DE LAS CONDICIONES LABORALES EN LA LEY 9/2017, DE 8 DE NOVIEMBRE, DE CONTRATOS DEL SECTOR PÚBLICO*
}

\author{
Susana RodríGUEZ EsCANCIANO \\ Catedrática de Derecho del Trabajo \\ y de la Seguridad Social \\ Facultad de Derecho \\ Universidad de León \\ srode@unileon.es
}

\begin{abstract}
RESUMEN
Aun cuando la contratación pública no está diseñada para que sea un medio de fomento directo ni de control específico de medidas sociales, la verdad es que puede tener un extraordinario poder de conformación sobre el tejido empresarial; no en vano quienes quieran acceder a los procedimientos de licitación pública y resultar finalmente adjudicatarios deben cumplir forzosamente con las condiciones y exigencias predefinidas de antemano por los poderes adjudicadores. Bajo tal premisa, la Ley 9/2017, de 8 de noviembre, de Contratos del Sector Público, apuesta por la incorporación transversal y preceptiva de criterios sociales en las distintas fases del proceso de contratación con el fin de mejorar el régimen laboral de los trabajadores afectados.
\end{abstract}

Palabras clave: Contratos públicos, sector público, condiciones laborales, empresa, modulación estratégica, idoneidad empresarial.

\section{ABSTRACT}

Even if public recruitment is not thought to be a means of direct promotion or specific control of social measures truth is that it may have an incredible power of structure over company network. In fact, those who would like to have access to public procedures and eventually win them over, have to necessary fulfil the requirements and needs previously determined by the contracting authority. Under that premise Act 9/2017, 8 November of Contracts of the Public sector bets for mandatory and transversal social criteria throughout the various phases of contracting procedure so as to improve the working conditions of the affected workers.

* Este trabajo se ha realizado en el marco del proyecto de investigación DER 2017-83864-R, financiado por el Ministerio de Economía, Industria y Competitividad, bajo el título «La sostenibilidad como idea rectora de las políticas públicas y de la prestación de servicios públicos para el bienestar de los ciudadanos». 
Susana Rodríguez Escanciano La apuesta por la mejora de las condiciones laborales...

Keywords: Public Contracts, Public Sector, Working Conditions, Company strategic Modulation, Company suitability.

\section{ZUSSAMENFASSUNG}

Obwobl die Anstellung im Staatssektor weder ein direktes Mittel zur Arbeitsförderung ist noch eine spezifische Regulierung von sozialen Maßnabmen darstellt, so ist es doch wabr, dass sie eine gestaltende Auswirkung auf die Unternebmensstruktur ausüben kann. Nicht umsonst müssen die Bewerber, die bei den öffentlichen Ausschreibungen zugelassen und Erfolg haben wollen, zwangsläufig die vorgegebenen Bedingungen und Anforderungen der Vergabebehörden erfüllen. Unter dieser Prämisse tritt das Gesetz 9/2017 vom 8. November über Verträge im Staatssektor in Kraft, das sich für die übergreifende und verbindliche Einbeziehung von sozialen Kriterien in die verschiedenen Phasen der Anstellung einsetzt, um den arbeitsrechtlichen Status der betroffenen Arbeitnehmer zu verbessern.

Schlüsselwörter: öffentliche Anstellungsverträge, Staatssektor, Arbeitsbedingungen, Unternehmen, strategische Modulation, unternehmerische Geeignetheit.

SUMARIO: -I. LA «MODULACIÓN ESTRATÉGICA»DEL ENTRAMADO EMPRESARIAL DESDE LAS NORMAS DE CONTRATACIÓN PÚBLICA.-II. LA INCORPORACIÓN TRANSVERSAL DE CONDICIONES SOCIALES A LO LARGO DEL PROCESO DE CONTRATACIÓN.-III. LA EXIGENCIA DE IDONEIDAD EMPRESARIAL EN LA FASE DE LICITACIÓN.-1. Prohibiciones para contratar. La preceptiva trayectoria empresarial previa libre de tachas.-2. Acreditación de aptitud y solvencia. La lucha contra las meras apariencias.-IV. CRITERIOS DE ADJUDICACIÓN DE CONTENIDO SOCIAL.-1. Libertades económicas versus comportamientos empresariales socialmente responsables.-2. Asuntos Laval y Viking.-3. El caso Ruffert.-4. El asunto Bundesdruckerei.-5. El asunto RegioPost.-6. Avances del ordenamiento interno.-7. La exclusión de ofertas anormalmente bajas. La apuesta por el cumplimiento de los convenios sectoriales en cuanto a condiciones salariales se refiere.-8. Presupuesto base de la licitación.- 9. Utilización de criterios de desempate de contenido social a la hora de adjudicar el contrato. Claras medidas de fomento del empleo «selectivo».-V. CONDICIONES ESPECIALES DE EJECUCIÓN.-1. La colaboración de los adjudicatarios con determinados estándares sociales.-2. Consecuencias del incumplimiento.- - 3. Causas de resolución del contrato como garantía en el percibo de las retribuciones.-VI. CONCLUSIÓN.

\section{LA «MODULACIÓN ESTRATÉGICA» DEL ENTRAMADO EMPRESARIAL DESDE LAS NORMAS DE CONTRATACIÓN PÚBLICA}

Bajo una afanosa búsqueda de eficacia, la Administración Pública puede acudir, a la hora de prestar servicios a los ciudadanos, a una ges- 
tión indirecta por medio de sujetos privados, quienes, tras un proceso reglamentado abierto a la competencia, asumen la realización material de ciertas parcelas asociadas a las prerrogativas de aquélla. Desde tal premisa, aun cuando la contratación pública no está diseñada para que sea un medio de fomento directo ni de control específico de medidas sociales, la verdad es que puede tener un extraordinario poder de conformación social sobre el tejido empresarial; no en vano quienes quieran acceder a los procedimientos de licitación pública y resultar finalmente adjudicatarios de un contrato público deben cumplir forzosamente con las condiciones y exigencias predefinidas de antemano por los poderes adjudicadores ${ }^{1}$.

Es más, las propias instituciones europeas han mantenido (e incluso alentado) la posibilidad de utilizar la contratación administrativa con el fin último de afianzar comportamientos empresariales beneficiosos para el interés general, siempre y cuando los criterios sociales adoptados estén vinculados al objeto del concreto contrato que es causa de la correspondiente licitación y, además, sean compatibles con las libertades y principios en los que se fundamenta el sistema comunitario de contratación pública: suprimir las trabas a la libre circulación de mercancías y a la libertad de establecimiento y de prestación de servicios ${ }^{2}$.

Bajo tal perspectiva, ya la Directiva 2004/18, de 31 de marzo, sobre coordinación de los procedimientos de adjudicación de los contratos públicos de obras, de suministro y de servicios, reconoció expresamente, en su art. 27, la posibilidad de que el poder adjudicador pueda establecer obligaciones relativas a la fiscalidad, a la protección del medio ambiente y, por lo que aquí interesa, a la tutela de las condiciones de trabajo ${ }^{3}$. Con mayor profundidad, a la vista de la Estrategia Europa 2020, que adopta como uno de sus objetivos básicos el de lograr una economía con alto nivel de empleo y cohesión social, la nueva Directiva 2014/24, de 26 de febrero, sobre contratación pública, transpuesta al ordenamiento jurídico español por la nueva Ley 9/2017, de 8 de noviembre, de Contratos del Sector Público (LCSP), adopta, entre sus postulados básicos, el diseño de políticas de progreso de la Unión Europea en materia social; no en

${ }^{1}$ S. Rodríguez Escanciano, Cláusulas sociales y licitación púbica, Sevilla, Instituto Andaluz de Administración Pública, 2009, pp. 13 y ss.

2 A. Casares Marcos, «Función de las cláusulas sociales en relación con la prestación contractual: la definición del objeto contractual y su introducción como condición especial», en B. García Romero y M. M. PRADO LóPez (dirs.), Innovación social en la contratación administrativa: las cláusulas sociales, Cizur Menor, Aranzadi, 2017, pp. 113-156.

3 E. Román VACA, «Las cláusulas sociales en la licitación pública y la aplicación del ¿aberrante? Derecho comunitario», Revista de Derecho Social, núm. 36 (2006), p. 193. 
vano hace referencia a los aspectos de esta naturaleza en diversos preceptos relativos a la definición del objeto del contrato (art. 62), en los motivos de exclusión de contratistas (art. 57), en los criterios de adjudicación (art. 67) y en las condiciones de ejecución (art. 70) ${ }^{4}$. Esta Directiva afianza la senda hacia la denominada «utilización estratégica de las reglas de la contratación administrativa»o, dicho en otros términos, hacia la «modulación teleológica de las reglas de la contratación pública» ${ }^{5}$, postulado de gran importancia atendiendo a las cifras manejadas por la propia Comisión Europea que ponen de manifiesto cómo esta actividad representa casi el 20 por 100 del PIB de la Unión ${ }^{6}$.

\section{LA INCORPORACIÓN TRANSVERSAL DE CONDICIONES SOCIALES A LO LARGO DEL PROCESO DE CONTRATACIÓN}

La posibilidad de utilizar la política de contratación pública como instrumento de garantía social se enmarca en el siempre complejo fenómeno de las relaciones triangulares, donde la Administración interviene como uno de los vértices por medio de los vínculos jurídico-contractuales que establece con el empleador privado, sin conexión jurídica formal con los trabajadores de este último, pero, desde su posición, condicionando el régimen laboral ${ }^{7}$.

Así, con la intención de dar cumplimiento al objetivo de «diseñar un sistema de contratación pública más eficiente, transparente e íntegro, mediante el cual se consiga el mejor cumplimiento de los objetivos públicos, tanto a través de la satisfacción de las necesidades de los órganos de contratación como mediante una mejora de las condiciones de acceso y participación en las licitaciones públicas de los operadores económicos y, por supuesto, a través de la prestación de mejores servicios a los usuarios

${ }^{4}$ A. Romero Ruiz, «Las cláusulas sociales en el proyecto de Ley de Contratos del Sector Público y el nuevo paradigma de la contratación pública», Revista Vasca de Administración Pública, núm. 108 (2017), pp. 127 y ss.

${ }^{5}$ C. Molina Navarrete, «Cláusulas sociales, contratación pública: del problema de legitimidad al de sus límites», Temas Laborales, núm. 135 (2016), pp. 79 y ss.

${ }^{6} \mathrm{~J}$. M. MARTínez FernÁNDEZ, «Avanzando en la contratación socialmente responsable: de la recomendación a la obligación», Observatorio de Contratación Pública, disponible en http://www.obcp.es/index.php/mod.opiniones/mem.detalle/id.199/relcategoria.201/relmenu.3/chk.fae414ebb6f848c52e40ddc2faf7468e.

${ }^{7}$ J. Cruz Villalón, «Claves laborales de la participación privada en la actuación pública», Temas Laborales, núm. 135 (2016), p. 17. 
de los mismos», el art. 1.3 LCSP prevé que «en toda contratación pública se incorporarán de manera transversal y preceptiva criterios sociales $(\mathrm{y}$ medioambientales) siempre que guarden relación con el objeto del contrato», en la convicción de que su inclusión proporciona una mejor relación calidad-precio en la prestación contractual, así como una mayor y mejor eficiencia en la utilización de los fondos públicos.

Buena muestra de tan amplio propósito de aplicación transversal de condiciones sociales en todo el proceso de contratación puede encontrarse en el art. 122.2 LCSP, que exige la introducción en los pliegos de cláusulas administrativas particulares, definidores de la dinámica de la relación contractual entre los derechos y obligaciones de cada una de las partes, de «las consideraciones sociales, laborales y ambientales que como criterios de solvencia, de adjudicación o como condiciones especiales de ejecución se establezcan». Se mencionan así los tres momentos que, tal y como se tratará de explicar en las páginas siguientes, adquieren importancia capital a la hora de introducir cláusulas para la salvaguarda de los derechos de los trabajadores en los procesos de contratación pública: en la acreditación de capacidad y solvencia por parte de los licitadores, en la adjudicación del contrato y durante la ejecución.

\section{LA EXIGENCIA DE IDONEIDAD EMPRESARIAL EN LA FASE DE LICITACIÓN}

Cuando la Administración comitente y el empresario adjudicatario celebran un contrato administrativo, su ejecución supone disponer la organización de medios materiales y humanos del segundo al servicio de la primera por razón de ese encargo, de modo que el objeto del contrato celebrado entre ambos sujetos conlleva la puesta en funcionamiento de la organización productiva del mencionado empresario como parte accidental del ciclo de actuación de la Administración ${ }^{8}$. No puede extrañar, por tanto, que el candidato a contratar con un Ente administrativo deba poseer más requisitos de capacidad y solvencia que los exigidos al particular que quiere convenir un vínculo contractual con otro sujeto privado, hasta el punto de que la capacidad de quien quiere optar al estatus de futuro contratista o concesionario público se encuentra absolutamente

${ }^{8}$ V. Manteca Velarde, «El derecho a ser contratista», Contratación Administrativa Práctica, núm. 40 (2005), pp. 33 y ss. 
determinada ${ }^{9}$, circunstancia que, sin duda, redundará en beneficio de los trabajadores implicados.

\section{Prohibiciones para contratar. La preceptiva trayectoria empresarial libre de tachas}

El Real Decreto Legislativo 3/2011, de 14 de noviembre, por el que se aprueba el anterior texto refundido de la Ley de Contratos del Sector Público (TRLCSP), ya recogía varias limitaciones tendentes a asegurar que los contratistas y concesionarios están sujetos a la ley y al Derecho, evitando la licitación de aquellos sujetos que infringen o incumplen el ordenamiento jurídico, pudiendo mencionar, por lo que aquí interesa, los siguientes vetos mantenidos por la actual $\operatorname{LCSP}^{10}$ :

1. Condena mediante sentencia firme por delitos contra los derechos de los trabajadores.

2. Sanción firme por infracción grave en materia profesional, de integración laboral y de igualdad de oportunidades y no discriminación de las personas con discapacidad, o de extranjería.

3. Sanción firme por infracción muy grave en materia laboral o social de acuerdo con el Real Decreto Legislativo 5/2000, de 4 de agosto, por el que se aprueba el texto refundido de la Ley de Infracciones y del Orden Social (LISOS), especialmente por no solicitar la afiliación inicial o el alta de los trabajadores que ingresen a su servicio, o solicitar la misma, como consecuencia de actuación inspectora, fuera del plazo establecido. A estos efectos se considerará una infracción por cada uno de los trabajadores afectados.

4. Haber solicitado la declaración de concurso voluntario, haber sido declaradas insolventes en cualquier procedimiento o hallarse declarados en concurso, lo cual redundará en la garantía del cobro de los salarios por los trabajadores adscritos a la contrata o concesión administrativa.

5. No encontrarse al corriente de las obligaciones en materia de Seguridad Social, entendiendo excluidos los casos de deudas aplazadas, fraccionadas o cuando se hubiera alcanzado su suspensión con ocasión de la impugnación de tales deudas.

9 J. Bermejo Vera, «Las prohibiciones de contratar en la Ley de Contratos del Sector Público», Revista Aragonesa de Administración Pública, núm. extra. 10 (2008), pp. 109 y ss.

${ }^{10} \mathrm{H}$. Gonçalvez PequeÑo, El contratista de la Administración Pública, Madrid, Marcial Pons, 2000, pp. 155-156. 
6. En el caso de empresas con cincuenta o más trabajadores no cumplir con el requisito de que al menos el 2 por 100 de sus empleados sean trabajadores con discapacidad en los términos previstos en el art. 42 del Real Decreto Legislativo 1/2013, de 29 de noviembre, por el que se aprueba el texto refundido de la Ley General de Derechos de las Personas con Discapacidad, que aclara cómo se formulará el cómputo refiriéndose a la plantilla total de la empresa, cualquiera que sea el número de centros de trabajo de aquélla y cualquiera que sea la forma de contratación laboral que vincule a los trabajadores. Igualmente se entenderá que estarán incluidos en dicho cómputo los trabajadores con discapacidad que se encuentren en cada momento prestando servicios en virtud de los contratos de puesta a disposición celebrados con empresas de trabajo temporal. A tenor de este precepto se admite, no obstante, lo cual desvirtúa bastante la eficacia de la prohibición para contratar, que de manera excepcional las empresas puedan quedar exentas de esta obligación de forma parcial o total, bien a través de acuerdos recogidos en la negociación colectiva sectorial de ámbito estatal y, en su defecto, de ámbito inferior, a tenor de lo dispuesto en el art. 83.2 y $3 \mathrm{ET}$, debidamente comunicada a la autoridad laboral, y siempre que en ambos supuestos se apliquen las medidas alternativas que se determinen reglamentariamente, en referencia a las tres siguientes: a) la suscripción de un contrato mercantil o civil con un centro especial de empleo o con un trabajador autónomo discapacitado, tanto para el suministro de materias primas, maquinaria, bienes de equipo o cualesquiera otros productos necesarios para el correcto desarrollo de la actividad propia de la empresa que opta por esta medida como para la prestación de servicios ajenos y accesorios a sus normales tareas; $b$ ) la colaboración con los enclaves laborales (regulados por Real Decreto 290/2004, de 20 de febrero), entendidos como el conjunto de trabajadores con discapacidad procedentes de un centro especial de empleo que son desplazados a una empresa ordinaria con el ánimo principal de favorecer el tránsito de estos trabajadores a un entorno laboral normalizado; c) la donación o patrocinio monetario para el desarrollo de actividades de inserción laboral y de creación de empleo de personas con discapacidad, cuando la entidad beneficiaria de dichas acciones de colaboración sea una fundación o una asociación de utilidad pública cuyo objeto social sea, entre otros, la formación profesional, la inserción laboral o la generación de empleo a favor de los discapacitados que permita la creación de puestos de trabajo para los mismos y, finalmente, su integración en el mercado laboral (art. 2.1 del Real 
Decreto 364/2005, de 8 de abril) ${ }^{11}$. Esta previsión fue introducida por la Ley 40/2015 en el TRLCSP.

Como ya consta, el nuevo texto legal mantiene todas estas prohibiciones, introduciendo únicamente una nueva en el art. 71.d) referida a las empresas de más de 250 trabajadores que no hayan cumplido con la obligación legal de contar con un plan de igualdad de acuerdo con lo previsto en el art. 45 de la Ley Orgánica 3/2007, de 22 de marzo, para la Igualdad Efectiva de Mujeres y Hombres (LOIEMH). Pese a la importancia de esta última previsión en cuanto a la salvaguarda del principio de no discriminación laboral entre sexos, cabe realizar una crítica en relación con la técnica jurídica utilizada, pues la referencia expresa a las empresas de más de 250 trabajadores (escasas en términos cuantitativos en el panorama empresarial español) parece limitar la aplicación de las posibilidades que otorga la LOIEMH en cuanto a la existencia de planes de igualdad en empresas de menores dimensiones, esto es, «cuando así se establezca en el convenio colectivo que sea aplicable, en los términos previstos en el mismo» (apartado 3 del art. 45) o «previa negociación o consulta, en su caso, con la representación legal de los trabajadores y trabajadoras, cuando la autoridad laboral hubiera acordado en un procedimiento sancionador la sustitución de las sanciones accesorias por la elaboración y aplicación de dicho plan, en los términos que se fijen en el indicado acuerdo» (apartado 4 del art. 45) ${ }^{12}$. No hay que olvidar, a la postre, que las prohibiciones han de interpretarse de forma restrictiva.

Por lo demás, se detiene la nueva LCSP en detallar cómo se puede acreditar el cumplimiento de la obligación de contar con un plan de igualdad y también de la cuota de reserva del 2 por 100 para trabajadores discapacitados, haciendo mención, en primer lugar, al mecanismo de declaración responsable, habilitando también al Consejo de Ministros para que, mediante real decreto, establezca una forma alternativa de acreditación que, en todo caso, será bien mediante certificación del órgano administrativo correspondiente, con vigencia mínima de seis meses, o bien mediante certificación del correspondiente Registro de Licitadores, en los casos en que dicha circunstancia figure inscrita en el mismo» [art. 71.1.d)].

En fin, se echa de menos que la nueva LCSP no haya sido más incisiva en cuanto a las prohibiciones para contratar de las empresas infractoras

${ }^{11}$ F. VALDÉs DAL-RÉ, «Derechos en serio y personas con discapacidad», Relaciones Laborales, núm. 12 (2005), pp. 9 y ss.

12 E. Sierra Hernáiz, «El papel de los planes de igualdad en la implantación de medidas de igualdad efectiva en las empresas», Lan Harremanak, núm. 38 (2017), pp. 204 y ss. 
en materia social o laboral, incluida la prevención de riesgos laborales, atendiendo a la relevancia que en la siniestralidad laboral juegan las contratas o concesiones administrativas, las cuales llevan aparejados, directa o indirectamente, un cúmulo de factores de riesgos que actúan sobre los empleados y determinan su mayor vulnerabilidad. No se alcanza a comprender por qué el art. 71 LCSP (al igual que hacía su precedente) eleva la entidad de la infracción, capaz de hacer aplicable la prohibición de contratar con la Administración, de grave a muy grave cuando se refiere a la «materia social» y no para las infracciones reseñadas en el mismo párrafo «en materia profesional, en materia de integración laboral y de igualdad de oportunidades y no discriminación de las personas con discapacidad», pues en este último caso basta con que se trate de una infracción grave. La Administración debería seguir acogiéndose a la imprecisa expresión «materia profesional» para vetar la contratación con empresas que hayan sido sancionadas con carácter grave en el marco laboral, pero de momento la discrecionalidad queda servida. Por lo demás, es menester recordar que el carácter firme exigido sólo se produce en el doble supuesto de que la resolución administrativa haya sido consentida por no haber sido objeto de la correspondiente impugnación en la vía jurisdiccional o porque, producida la misma, se haya resuelto en dicha vía sin posibilidad de ulterior recurso.

En todo caso, se trata de apartar del tráfico jurídico a determinados sujetos que, por su conducta antecedente en el propio sector en que se desenvuelven, no cuentan con un nivel indispensable de credibilidad personal, y pueden crear, además, un riesgo adicional ante la imposibilidad de asumir responsabilidades. Lo difícil será detectar que en la empresa concurre la tacha aquí enunciada. Nuevas perspectivas abre, a este respecto, la implementación de la administración electrónica y, cómo no, el Real Decreto 597/2007, de 4 de mayo, sobre publicación de sanciones administrativas impuestas por infracciones muy graves en materia de prevención de riesgos laborales, sanciones que se harán públicas en el Boletín Oficial del Estado o en el Boletín Oficial de las Comunidades Autónomas de acuerdo con el correspondiente ámbito competencial, incluyendo, lógicamente, el nombre o razón social de la empresa sancionada y toda una serie de datos identificativos de la misma. 


\section{Acreditación de aptitud y solvencia. La lucha contra las meras apariencias}

Las reglas sobre capacidad e idoneidad de las empresas aseguran la elección por parte de la Administración de colaboradores aptos para el desempeño de funciones públicas, lo cual equivale a rechazar al oportunista, a quien carece de la entidad necesaria para acometer una serie de prestaciones que se consideran esenciales para la satisfacción de necesidades generales con arreglo a estándares de eficacia. Así, a los sujetos que quieran contratar con la Administración se les exige, al igual que ya lo hacía el TRLCSP, aparte de la lógica «capacidad de obrar», que acrediten su solvencia «económica y financiera y técnica o profesional», en el bien entendido sentido de que mientras la capacidad para contratar con la Administración es necesaria siempre, la solvencia, por el contrario, se gradúa en función de la envergadura y condiciones específicas de cada contrato, debiendo acreditarse documentalmente o de forma automática mediante la oportuna clasificación, que puede ser objeto de suspensión o revisión según las cambiantes circunstancias de la vida de la empresa (art. 65 LCSP) ${ }^{13}$.

Teniendo en cuenta que la Administración tiene en la solvencia el mejor instrumento para dominar el contrato - no en vano constituye un sinónimo de suficiencia para la ejecución— ${ }^{14}$, la LCSP, además de dedicar el actual art. 85 a regular de manera más detallada los medios para acreditar solvencia económica y financiera por parte del licitador (volumen de negocio, seguro de responsabilidad civil, patrimonio neto...), procede a incorporar en el contrato de obra [art. 88.e) LCSP], en el de servicios

\footnotetext{
${ }^{13}$ M. FuERTES LÓPEZ, El contratista y el subcontratista ante las Administraciones Públicas, Madrid, Marcial Pons, 1997, p. 71.

${ }^{14}$ En este contexto puede hacerse mención a la Resolución del Tribunal de Contratación Administrativa de Murcia 2/2017, de 13 de enero, que considera adecuada la exigencia a los licitadores de aportar un certificado acreditativo del cumplimiento de la norma OHSAS 18001 del Sistema de Gestión de la Seguridad y Salud en el Trabajo al objeto de homologar la prestación de los servicios de seguridad y control de accesos por parte de empresas de seguridad privada en diversos edificios y recintos de la Comunidad Autónoma. En cambio, por Resolución 186/2017, de 21 de junio, del Tribunal Administrativo de Contratación Pública de la Comunidad de Madrid, se ha anulado la puntuación otorgada a la adjudicataria de un contrato de servicios complementarios, mantenimiento, limpieza y conserjería de los edificios, colegios e instalaciones deportivas de un distrito porque, aunque ha declarado que subcontrataría el 100 por 100 de la prestación a un centro especial de empleo, no puede obtener los puntos que le han sido asignados porque la adjudicataria no acredita que posea una solvencia propia mínima más allá de la subcontratación.
} 
[art. 90.g) LCSP] y en el resto de contratos distintos de los de obras, suministros y servicios [art. 91 LCSP por remisión al anterior], entre la enumeración de los medios para valorar la solvencia técnica, la obligación del titular de la organización productiva de efectuar una «declaración sobre la plantilla media anual de la empresa» y, como novedad, «del número de directivos durante los tres últimos años». Ello permite ofrecer una dimensión real de la actividad productiva y de las proyecciones de futuro al margen de desviaciones como pueden ser las contrataciones de personal a través de empresas de trabajo temporal o de sucesivos contratos a termino de escasa duración. Facilita, por tanto, una dimensión constante del volumen de empleo de la entidad empresarial por encima de los altibajos de las cargas de trabajo momentáneas, lo cual redundará en una mayor eficacia de la prestación de la actividad pública a favor de los ciudadanos y, al tiempo, reducirá los índices de inestabilidad laboral obrantes en el mercado de trabajo español y sus deplorables efectos: descualificación, inseguridad profesional y personal, siniestralidad, disminución del consumo, etcétera.

\section{CRITERIOS DE ADJUDICACIÓN DE CONTENIDO SOCIAL}

Cierto es que la evaluación de las ofertas para la adjudicación de un contrato público debe realizarse en virtud de criterios objetivos que respondan a la finalidad de seleccionar la mejor y la más ventajosa propuesta en nombre de la transparencia, la libre competencia y la no discriminación entre los posibles licitadores ${ }^{15}$. No menos verdad resulta que el sector público, a diferencia del privado, no resulta absolutamente libre para contratar, sino que se encuentra condicionado a la selección e identificación de la oferta que proporcione la mejor relación «calidad/precio», pero esta expresión no tiene por qué remitir a la proposición que implique una mayor ventaja económica stricto sensu, sino que puede dar lugar a la admisión, apreciación y baremación de otras prebendas indirectas. No cabe duda que la principal finalidad del sistema de contratación pública debe ser la institucionalización de un modelo de competencia funcional, eficaz y efectiva, el cual debe tomar en consideración los costes sociales reales que el propio sistema competitivo genera. Es más, el Libro Verde de la Contratación Pública de 27 de noviembre de 1996 considera que uno de los objetivos del mercado inte-

15 S. Vernia Trillo, «La inclusión de las cláusulas sociales en la contratación pública», Revista Aragonesa de Administración Pública, núm. 20 (2002), p. 439. 
rior y, por tanto, de la contratación pública es, precisamente, la creación de empleo en favor de aquellos colectivos que más lo necesitan ${ }^{16}$, razón por la cual para determinar la adjudicación de un contrato público a una determinada empresa se pueden manejar criterios que integren aspectos sociales. Ahora bien, tampoco cabe perder de vista que la normativa europea reguladora de los procedimientos de contratación pública atiende prioritariamente a un objetivo económico, por lo que las decisiones al respecto han de ser adoptadas con fundamento en consideraciones esencialmente monetarias ${ }^{17}$, admitiendo, no obstante, ciertas modulaciones de calidad social.

\section{Libertades económicas versus comportamientos empresariales socialmente responsables. Un apunte desde el Derecho comunitario}

Aun partiendo de una perspectiva favorable a la inclusión de objetivos sociales en los contratos públicos, sin embargo, la admisibilidad de la utilización debe respetar las libertades comunitarias y contribuir a la consecución de un mercado interior único. La legislación europea al respecto ha favorecido la apertura a la competencia de las empresas a través de procesos de selección transparentes, contemplando también la posibilidad de interponer recursos contra los órganos de contratación que no respetan sus obligaciones. En materia de adjudicación de contratos públicos, las Administraciones están supeditadas al cumplimiento de los postulados de libre circulación de mercancías, libertad de establecimiento y libre prestación de servicios, así como de los principios derivados de estas libertades, en especial el de igualdad de trato y no discriminación entre los candidatos, el de reconocimiento mutuo, el de proporcionalidad y el de transparencia ${ }^{18}$.

El núcleo del problema radica, por tanto, en la necesidad de hacer compatibles «los parámetros de igualdad y competencia en la licitación y adjudicación que presiden la legislación contractual pública comunitaria con la utilización de las decisiones de los órganos de contratación como vehículo de las políticas de fomento y de acción y protección social», mani-

${ }^{16}$ COM (96) 583 final, de 27 de noviembre, p. 2.

17 J. M. Gimeno Feliú (coord.), «Los procedimientos y criterios de adjudicación y la posibilidad de valorar los aspectos sociales y medioambientales», en Contratación de las Administraciones Públicas: análisis práctico de la nueva normativa sobre contratación pública, Barcelona, Bosch, 2004, p. 67.

18 SSTJCE 76/90, de 25 de julio de 1991, asunto Säger, y 164/99, de 24 de enero de 2002, asunto Portugaia Construcoes. Vid. también G. VARA ArRIBAS, «Novedades en el debate europeo sobre contratación pública», Revista Española de Derecho Europeo, núm. 26 (2008), p. 128. 
festadas, en este caso, en la adjudicación de los contratos a favor de los sujetos que cumplen determinados estándares de calidad social ${ }^{19}$.

No cabe olvidar que las instituciones europeas han mantenido (e incluso alentado) la posibilidad de utilizar la contratación administrativa con el fin último de afianzar comportamientos empresariales beneficiosos para el interés general, pero siempre y cuando los criterios sociales adoptados estén vinculados al objeto del concreto contrato que es causa de la correspondiente licitación y, además, sean compatibles con las libertades y principios en los que se fundamenta el sistema de contratación pública: suprimir las trabas a la libre circulación de mercancías y a la libertad de establecimiento y de prestación de servicios, y, por tanto, proteger los intereses de los operadores económicos establecidos en un Estado miembro que deseen ofrecer sus bienes o servicios a las entidades adjudicadoras situadas en otro Estado miembro ${ }^{20}$.

Desde tal premisa, no cabe olvidar que la restricción a la libertad de prestación de servicios a través de normas internas ha sido admitida muy excepcionalmente en algunos casos por la Corte Comunitaria, permitiendo que las legislaciones de los Estados miembros puedan constituir una excepción legítima a la hegemonía de dicha libertad ${ }^{21}$, idea de la cual se hace eco el art. 3.1 de la Directiva 96/71, de 16 de diciembre, sobre el desplazamiento de trabajadores efectuado en el marco de una prestación de servicios transnacional, donde se recogen las materias mínimas que resultarán de aplicación a los trabajadores destacados temporalmente en otro Estado miembro, limitando de manera decisiva la competencia a la baja sobre los costes sociales, quedando garantizado su cumplimiento también por la actual Directiva 2014/6722.

Ahora bien, en los años transcurridos entre la discusión y aprobación de la Directiva 96/71 y el momento en el cual se promulgó la deroga-

19 J. M. MiRanda Boto, «Contratación pública y cláusulas de empleo y condiciones de trabajo en el Derecho de la Unión Europea», Lex Social, núm. 2 (2016), pp. 69 y ss.

${ }^{20}$ SSTJCE 380/98, de 3 de octubre de 2000; 94/99, de 7 de diciembre de 2000; 92/2000, de 18 de junio de 2002; 470/99, de 12 de diciembre de 2002; 373/00, de 27 de febrero de 2003, o 346/06, de 3 de abril de 2008.

${ }^{21}$ SSTJCE 279/80, de 17 de diciembre de 1981, asunto Webb; 113/89, de 27 de marzo de 1989, asunto Rush Portuguesa, o 513/99, de 17 de septiembre de 2002, asunto Concordia Bus Finland, que admite la valoración, como criterio de adjudicación del proceso de licitación del contrato para la adquisición de autobuses para la prestación del servicio público de transporte en la ciudad de Helsinki, de la menor cantidad de emisión de $\mathrm{CO}_{2}$ de los vehículos a la atmósfera.

${ }^{22}$ C. Molina Navarrete, «Cláusulas sociales, contratación pública...», op. cit., pp. 79 y ss. 
da Directiva 2004/18, la jurisprudencia del Tribunal de Justicia ha venido matizando la previsión anterior para entender que no es posible incorporar cargas adicionales a la libertad de establecimiento dentro del marco de la Unión Europea $^{23}$. Como con acierto ha precisado este alto órgano judicial, «la posibilidad de que los organismos contratantes utilicen como criterio de valoración de las ofertas una condición relacionada con la mejora o el incremento del empleo $\mathrm{u}$ otros aspectos de contenido social es plenamente admisible, siempre que ésta respete todos los principios fundamentales del Derecho comunitario y, en particular, el principio de no discriminación que se deriva de las disposiciones del Tratado en materia de derecho de establecimiento y de prestación de servicios, y, cómo no, el principio de transparencia en la licitación» ${ }^{24}$.

Realmente, lo que el Tribunal de Justicia de la Comunidad Europea postula (y la derogada Directiva 2004/18 refrendaba) es la compatibilidad con el ordenamiento comunitario de aquellas cláusulas o condiciones sociales que no operen como requisitos de admisión y/o exclusión de ciertas empresas en los procedimientos de contratación ni como criterios adjudicadores del contrato, pues nunca podrán suponer vulneración alguna de los citados principios comunitarios de igualdad y publicidad. Como no podía ser de otra manera, tal interpretación judicial provocó una retirada de la objeción a la utilización de meros criterios de desempate de contenido social en la valoración de propuestas por parte de la Comisión Europea, que procedió a corregir así el Dictamen motivado de 21 de diciembre de 2001 a través de otro con fecha de 8 de febrero de 2002, en virtud del cual no cabe alegar ya ningún obstáculo al establecimiento de pautas sociales para deshacer el empate entre propuestas equivalentes, «siempre que la evaluación se efectúe desde una perspectiva económica y se respeten en todos los casos las normas de transparencia y el principio de no discriminación» ${ }^{25}$. Interpretación de la que participaron las más importantes instancias españolas, léase tanto el Consejo de Estado $^{26}$ como el Consejo Económico y Social ${ }^{27}$, al entender que la adju-

23 SSTJCE 19/92, de 31 de marzo de 1993, asunto Kraus; 55/94, de 30 de noviembre de 1995, asunto Gebhard; 369/96 y 376/96, de 23 de noviembre de 1999, asunto Arblade, y 49/98, 50/98, 52/98, 54/98 y 68 a 71/98, de 25 de octubre de 2001, asunto Finalarte Sociedade de Construcao Civil Ltda.

${ }^{24}$ STJCE de 26 de septiembre de 2000, asunto Nord-pas-de-Calais.

${ }^{25}$ C. Molina NavarRete, «Cláusulas sociales, contratación pública...», op. cit., pp. 79 y ss.

26 Dictamen 4468/1998, de 22 de diciembre.

27 Dictamen 5/1998, de 27 de mayo. 
dicación del contrato «no debe limitarse a una mera consideración presupuestaria, sino que ha de venir integrada en el conjunto de políticas que persiguen los poderes públicos [...] pudiendo utilizar criterios adicionales de desempate una vez que las ofertas han sido valoradas y comparadas desde el punto de vista de los criterios de adjudicación y nos encontramos con ofertas equivalentes» ${ }^{28}$.

Por su parte, la Comunicación de la Comisión de 2 de julio de 2002, relativa a «La responsabilidad social de las empresas: una contribución empresarial al desarrollo sostenible», se esfuerza en dejar claro que las Administraciones Públicas, incluida la Comisión, deben integrar los principios de la responsabilidad social en sus propios sistemas de gestión y en las relaciones con sus interlocutores, inclusive en sus propios procedimientos de contratación pública, afirmándose en esta materia que «las comunicaciones interpretativas de la Comisión sobre las disposiciones comunitarias aplicables a los contratos públicos y la integración de aspectos sociales (y medioambientales) en los mismos han servido para clarificar el abanico de posibilidades que ofrece el marco jurídico comunitario a los compradores públicos que deseen incluir consideraciones sociales (y medioambientales) en los procedimientos de contratación pública, respetando al mismo tiempo el principio de oferta más ventajosa para los contribuyentes y la igualdad de acceso para todos los proveedores comunitarios». De este modo, el hecho de constituir una empresa socialmente responsable puede convertirse en una ventaja a la hora de concurrir a un proceso de contratación pública, idea que reitera la Comunicación de la Comisión al Parlamento Europeo, al Consejo y al Comité Económico y Social Europeo de marzo de 2006 titulada «Poner en práctica la asociación para el crecimiento y el empleo: hacer de Europa un polo de excelencia de la responsabilidad social de las empresas», y que recoge también el Informe del Parlamento Europeo sobre la «responsabilidad social de las empresas de subcontratación en las cadenas de suministro», aprobado el 18 de febrero de 2009, pero como mero parámetro de desempate, una vez valoradas las propuestas.

${ }^{28}$ En este sentido vid. Informe 4/2000 de la Junta Consultiva de Contratación Administrativa de Cataluña e Informe 4/2002, de 5 de junio, de la Junta Consultiva de Contratación Administrativa de la Comunidad Valenciana. 


\section{Asuntos Laval y Viking}

No puede dejar de destacarse, en contrapartida — y pese a todos estos tímidos avances--, que desde los orígenes de la Unión, la liberalización de los mercados se ha venido identificando con una prohibición, vigente hasta nuestros días, de disposiciones y prácticas restrictivas que «hagan más onerosa la prestación de servicios, imponiendo cargas fiscales o de otro tipo» [letra $e$ ) del punto A del Programa general para supresión de las restricciones a la libre prestación de servicios] ${ }^{29}$. El Derecho del mercado interior de servicios nacía así con un mandato claro de supresión de costes innecesarios para los prestadores transnacionales, aunque en dicha fase inicial tal prohibición no alcanzaba a los costes laborales. Desde el Tratado de Niza se produce, sin embargo, una importante reordenación en el proceso europeo, cada vez más alejado del proyecto social (que en materia de trabajo lo enmarcaría el reconocimiento de derechos que corrigieran las situaciones de asimetría radical al alza entre trabajadores de los distintos Estados miembros) y más cercano al proyecto liberal de integración de los mercados, en el que la intervención se encuentra dentro de los objetivos de situar a Europa y a los países socios en mejores condiciones de competitividad en el contexto mundial. Será, además, la jurisprudencia que ha interpretado las disposiciones del Tratado en materia de libre prestación de servicios, que contiene el art. 56 TFUE, la que extienda esa prohibición inicial de afectación al ámbito sociolaboral, pasando éste a formar parte también de los presupuestos económico-normativos de la actuación comunitaria dirigida a eliminar las barreras reguladoras de los Estados, entendiendo que la aplicación de las normativas nacionales del país miembro de acogida a los prestadores de servicios no puede prohibir, obstaculizar o hacer menos interesantes las prestaciones de servicios por personas o empresas establecidas en otros Estados miembros, en la medida que tal aplicación genera gastos adicionales y supone un aumento de las cargas administrativas y económicas.

Cabe mencionar que el Tribunal de Justicia de la Unión Europea ha entendido en el asunto Laval que las medidas de conflicto adoptadas por los sindicatos suecos, que boicotearon a una empresa que se servía de trabajadores contratados en Letonia pagándoles la mitad de lo establecido en el convenio colectivo aplicable, no llegaron a superar el test de propor-

\footnotetext{
${ }^{29}$ DO, núm. 2, de 15 de enero de 1962, pp. 32-35.
} 
cionalidad, siendo consideradas, por tanto, excesivas ${ }^{30}$. En parecido sentido, en el asunto Viking ha sentado que no se consideró contrario al Derecho comunitario que una empresa letona, que cubre con transbordadores el trayecto entre Helsinki y Tallin (Estonia), pague a sus asalariados conforme a sus propias normas, con menos garantías y tutelas que lo hacen las empresas filandesas que cubren ese mismo trayecto ${ }^{31}$.

Así pues, el Tribunal de Justicia ha consagrado, como pauta interpretativa consolidada, el sacrificio del ejercicio sindical de los derechos de acción colectiva frente a la prohibición de obstaculizar la libre prestación de servicios, y ha considerado como prevalente, y casi incondicionado, el ejercicio de esta última libertad por parte de las empresas, incluyendo la posibilidad de aportar, mediante su desplazamiento, trabajadores propios low cost con las condiciones de trabajo y salariales de origen, sin que les sea aplicable la autotutela sindical del país de destino, haciendo abstracción de las exigencias de la Directiva 96/71 (actualmente garantizadas por la Directiva 2014/67), interpretadas, como puede comprobarse, en sentido muy estricto. La desaforada defensa de la libertad de prestación de servicios sacrificando la consideración de las condiciones de trabajo aplicadas en el lugar donde se desarrolla la actividad es una manifestación clara de la legitimidad del uso de aquella libertad con el solo fin de eludir las condiciones salariales y de trabajo y los derechos colectivos que asegura el ordenamiento constitucional y laboral en ese lugar. El establecimiento en un determinado país de bajas condiciones laborales permite desplazar trabajadores sujetos a ese ordenamiento por todo el territorio comunitario convirtiendo el ejercicio de esa libertad en un medio de elusión de la normativa laboral más protectora. Ello ha motivado encendidas críticas doctrinales, señalando que «en un momento en que se está hablando de la cláusula social en el ámbito de la globalización, la Unión Europea ampliada, bajo el principio de la libertad de circulación y la idea del mutuo reconocimiento, está favoreciendo auténticas formas de dumping social» ${ }^{32}$.

30 STJCE 341/05, de 18 diciembre de 2007.

31 STJCE 438/05, de 13 de diciembre de 2007.

32 C. Molina Navarrete, «Cláusulas sociales, contratación pública...», op. cit., pp. 79 y ss. 


\section{El caso Ruffert}

Cabe hacer referencia, en este deplorable contexto, a un pronunciamiento del Tribunal de Justicia de la Comunidad Europea en relación con la eventual aplicación de la Directiva 96/71 en el marco de la ejecución de un contrato de obra para la Administración Pública ${ }^{33}$. Concretamente, la materia controvertida que motivó la presentación de la cuestión prejudicial resuelta en la referida sentencia alude a la situación generada por el adjudicatario de un contrato público cuyo objeto consiste en edificar un centro penitenciario, empresa que recurrió, a su vez, a una contratista polaca para que participase en la ejecución del mismo. La Ley del Land de Baja Sajonia sobre la contratación pública, aplicable al vínculo administrativo, establecía que la entidad pública adjudicadora sólo podría encomendar contratos de obras y de transporte público de cercanías a empresas que abonasen a sus trabajadores los salarios fijados en los convenios colectivos vigentes en el lugar de ejecución de la prestación de servicios. Es claro que esta obligación legal imponía a las empresas constructoras de otros Estados miembros la necesidad de adaptar los salarios pagados a sus trabajadores atendiendo a la retribución, normalmente más elevada, aplicable en Alemania, lugar de ejecución del contrato. Tal exigencia redundaba en la pérdida por dichas empresas de la ventaja competitiva que se deriva a su favor de la posible aplicación de unos costes salariales más bajos. Por tanto, la obligación de respetar los convenios colectivos representaba un obstáculo para las personas físicas o jurídicas procedentes de Estados miembros distintos de la República Federal Alemana. Así pues, la cuestión que se planteó no era otra que determinar si el hecho de obligar legalmente a la entidad contratante a designar como adjudicatario de los contratos públicos de obras únicamente a las empresas que al licitar se comprometían por escrito a pagar a sus trabajadores, como contraprestación por la ejecución de los servicios correspondientes, como mínimo, la retribución prevista en el convenio colectivo aplicable en el lugar en que deben desarrollarse tales actividades, conculcaba (o no) la libre prestación de servicios ${ }^{34}$.

A este respecto, el Tribunal de Justicia de la Comunidad Europea establece la siguiente interpretación: «Al obligar a los adjudicatarios de con-

33 STJCE 346/06, de 3 de abril de 2008, asunto Rüffert.

34 J. A. Moreno Molina, «Se puede obligar a los licitadores y a sus contratistas a pagar un salario mínimo determinado al personal que llevará a cabo las prestaciones», Contratación Administrativa Práctica, núm. 141 (2016), pp. 106 y ss. 
tratos públicos de obras, y, de manera indirecta, a sus subcontratistas, a aplicar la retribución mínima prevista en el convenio colectivo "edificios y otras públicas" de Alemania, una norma como la Ley del Land puede imponer a los prestadores de servicios establecidos en otro Estado miembro en el que los salarios mínimos sean inferiores una carga económica adicional que puede impedir, obstaculizar o hacer menos interesante la ejecución de sus prestaciones en el Estado miembro de acogida. Por tanto, una medida como la controvertida puede constituir una restricción en el sentido del art. 48 TCE (art. 58 TFUE) ${ }^{35}$. En definitiva, entiende el Tribunal que, en el marco de la contratación pública, sólo puede imponerse a las empresas con sede en un Estado miembro que desplazan a sus trabajadores a otro país el cumplimiento de las leyes y convenios colectivos de aplicación general, pero no podría establecerse el obligado respeto de condiciones que superasen dichos mínimos, ya que se estaría vulnerando el principio de libre prestación de servicios ${ }^{36}$.

\section{El asunto Bundesdruckerei}

Llegados a este punto, cabe centrar la atención en un nuevo pronunciamiento del Tribunal de Justicia de la Unión Europea, donde se resuelve una cuestión prejudicial en la que la ciudad de Dortmund había licitado en un contrato público relativo a la digitalización de documentos y otras actividades, entre cuyas condiciones se exigía al vencedor que abonara a sus trabajadores y a los posibles empleados de las subcontratistas un salario mínimo por hora de 8,62 euros. Una de las empresas participantes en la licitación comunicó a la Administración que todas las prestaciones se realizarían en Polonia, donde tal condición no era viable. Frente a la negativa del Ayuntamiento de Dortmund a eximir del requisito a la empresa Bundesdruckerei, ésta impugnó la decisión ante un órgano de control de la competencia.

Como el Tribunal de Justicia le reconoce la naturaleza de órgano jurisdiccional, la cuestión prejudicial se elevó, entendiendo, de nuevo el Tribunal, que «la imposición, en virtud de una normativa nacional, de una retribución mínima a los subcontratistas de un licitador establecidos en

35 M. Rodríguez-PiÑERo y Bravo-FerRer, «El caso Rüffert: ¿una constitucionalización del dumping social?», Relaciones Laborales, núm. 15-16 (2008), pp. 83 y ss.

36 C. Molina Navarrete, «Cláusulas sociales, contratación pública...», op. cit., pp. 79 y ss. 
un Estado miembro distinto del de la entidad adjudicadora y en el que los salarios mínimos sean inferiores constituye una carga económica adicional que puede impedir, obstaculizar o hacer menos interesante la ejecución de sus prestaciones en el Estado miembro de acogida», de modo que «privaría, por ello, a los subcontratistas establecidos en este último Estado miembro de la posibilidad de obtener una ventaja competitiva de las diferencias existentes entre las cuantías de los salarios respectivos» ${ }^{37}$.

\section{El asunto RegioPost}

El Tribunal de Justicia de la Unión Europea cambia de criterio y se pronuncia sobre estas cuestiones en otro supuesto más próximo en el tiempo, en el que el Ayuntamiento de Landau, en el Palatinado alemán, estableció en el contexto de la adjudicación de un contrato público de servicios postales una cláusula por la cual imponía a los licitadores y a sus subcontratistas pagar un salario mínimo al personal que ejecutase las prestaciones objeto de esa licitación. RegioPost, una de las empresas que concurrió al concurso, consideró que dicha cláusula era ilegal y en su propuesta no respetó su contenido. Obviamente, el Ayuntamiento no la tuvo en cuenta, siendo impugnada ante los Tribunales la decisión municipal. En el curso del litigio se planteó la cuestión prejudicial para intentar determinar si la normativa europea era relevante en el caso estudiado, puesto que tanto la autoridad licitadora como la empresa (y las restantes empresas competidoras) se encontraban en Alemania, entendiendo el Tribunal que la exclusión de la licitación que imponía la norma no era gravosa en absoluto ${ }^{38}$.

\section{Avances del ordenamiento interno}

El apartado II de la Exposición de Motivos de la LCSP manifiesta que «por primera vez se establece la obligación de los órganos de contratación

\footnotetext{
37 STJCE 549/13, de 18 de septiembre de 2014, asunto Bundesdruckerei GMBH y Stadt Dortmund.

38 STJCE 115/14, de 17 de noviembre de 2015, asunto RegioPost. Vid. también D. TosCANi Giménez y A. Valenciano Sal, «Cambio de criterio del TJUE ante la posibilidad de fijar un salario mínimo a respetar en la ejecución de contratos en el ámbito de la contratación pública: comentario a la Sentencia del Tribunal de Justicia de la Unión Europea. Asunto C-115/14 (RegioPost GmbH amp; Go KG/Stadt Landau in der Pfalz), de 17 de noviembre de 2015», Unión Europea Aranzadi, núm. 1 (2016), pp. 89 y ss.
} 
de velar por que el diseño de los criterios de adjudicación permita obtener obras, suministros y servicios de gran calidad, concretamente mediante la inclusión de aspectos cualitativos, medioambientales, sociales e innovadores vinculados al objeto del contrato». Esta idea se desarrolla en el art. 145 LCSP, sentando en su párrafo $1 .^{\circ}$ que «la adjudicación de los contratos se realizará utilizando una pluralidad de criterios de adjudicación en base a la mejor relación calidad/precio», que «se evaluará con arreglo a criterios económicos y cualitativos», de modo que «los criterios cualitativos que establezca el órgano de contratación para evaluar la mejor relación cali$\mathrm{dad} /$ precio podrán incluir aspectos medioambientales o sociales vinculados al objeto del contrato» (párrafo $3 .^{\circ}$ ).

Para garantizar la inclusión de estos criterios cualitativos se exige que supongan, al menos, el 51 por 100 de la puntuación en los contratos de servicios listados en el anexo IV, así como en los contratos que tengan por objeto prestaciones de carácter individual. El art. 145.3.g) LCSP incide estableciendo que «en los contratos de prestación de servicios sociales, si fomentan la integración social de personas desfavorecidas o miembros de grupos vulnerables entre las personas asignadas a la ejecución del contrato, promueven el empleo de personas con dificultades particulares de inserción en el mercado laboral o cuando se trate de los contratos de servicios sociales, sanitarios o educativos a que se refiere la disposición adicional cuadragésima octava o de contratos intensivos en mano de obra, el precio no podrá ser el único factor determinante de la adjudicación». En todo caso, se descarta la posibilidad de que sólo aparezcan criterios cualitativos, pues en el último párrafo del art. 145.2 LCSP se dispone que éstos deberán ir acompañados de una pauta relacionada con los costes, que a elección del órgano de contratación podrá ser el precio o una regla basada en la rentabilididad ${ }^{39}$.

Por lo demás, al igual que sucedía en el TRLCSP, los criterios de adjudicación se establecerán en los pliegos de cláusulas administrativas particulares o en el documento descriptivo, y deberán figurar en el anuncio que sirva de convocatoria de la licitación. Según el art. 129 LCSP, el pliego podrá dar publicidad «a las disposiciones vigentes en materia de protección del empleo, igualdad de género, condiciones de trabajo y prevención de riesgos laborales e inserción sociolaboral de las personas con discapa-

39 M. R. Vallecillo GÁmeZ, «Aspectos sociolaborales de la nueva Ley de Contratos del Sector Público: innovaciones y puntos críticos», Revista de Trabajo y Seguridad Social (Centro de Estudios Financieros), núm. 417 (2017), p. 193. 
cidad, y a la obligación de contratar a un número o porcentaje específico de personas con discapacidad que serán aplicables a los trabajos efectuados en la obra o a los servicios prestados durante la ejecución del contrato», debiendo en este caso el órgano de contratación solicitar a los licitadores o a los candidatos en un procedimiento de adjudicación de contratos «que manifiesten haber tenido en cuenta en la elaboración de sus ofertas las obligaciones derivadas de las disposiciones vigentes en materia de [...] protección del empleo, igualdad de género, condiciones de trabajo, prevención de riesgos laborales e inserción sociolaboral de las personas con discapacidad, y a la obligación de contratar a un número o porcentaje especifico de personas con discapacidad».

Asimismo, dichos criterios sociales de adjudicación han de estar vinculados al objeto del contrato; exigencia establecida igualmente en el considerando 97 de la Directiva 24/2014 a fin de evitar, en última instancia, que «los poderes adjudicadores puedan estar autorizados a exigir a los licitadores que tengan establecida una determinada política de responsabilidad social en la empresa, sino que tendrán que particularizar la cláusula social en función del objeto y de la prestación contractual particular de que se trate».

Con anterioridad, se venía entendiendo que la vinculación al objeto del contrato implicaba que las cláusulas sociales incorporadas «han de poder ser realizadas por el adjudicatario a través de la materia a suministrar o de la prestación concreta a realizar, dado que se trata de un elemento que debe poder relacionarse intrínsecamente con la prestación principal, sin que pudiera afectar a cuestiones contingentes cuya justificación en nada alterara ni la forma de ejecutar la prestación ni los resultados de la misma ${ }^{40}$. Ahora, sin embargo, la propia LCSP indica que se entiende cumplida esta exigencia «cuando se refiera o integre las prestaciones que deban realizarse en virtud de dicho contrato, en cualquiera de sus aspectos y en cualquier etapa de su ciclo de vida, incluidos los factores que intervienen en los siguientes procesos: $a$ ) en el proceso específico de producción, prestación o comercialización de, en su caso, las obras, los suministros o los servicios, con especial referencia a formas de producción, prestación o comercialización medioambiental y socialmente sostenibles y justas; b) en el proceso específico de otra etapa de su ciclo de vida, inclu-

${ }^{40}$ Informes de la Junta de Contratación Administrativa del Estado 9/2009, de 31 de marzo; 11/1999, de 30 de junio; 44/2004, de 12 de noviembre, o 42/2006, de 30 de octubre. Asimismo, Resolución 44/2007, de 1 de marzo, del Tribunal de Cataluña, de Contratos del Sector Público. Vid. también Dictamen del Consejo de Estado 51/2006, de 25 de mayo. 
so cuando dichos factores no formen parte de su sustancia material». En concreto, la LCSP se refiere a: «El fomento de la integración social de personas con discapacidad, personas desfavorecidas o miembros de grupos vulnerables entre las personas asignadas a la ejecución del contrato $y$, en general, la inserción sociolaboral de personas con discapacidad o en situación o riesgo de exclusión social; la subcontratación con centros especiales de empleo o empresas de inserción; los planes de igualdad de género que se apliquen en la ejecución del contrato y, en general, la igualdad entre mujeres y hombres; el fomento de la contratación femenina; la conciliación de la vida laboral, personal y familiar; la mejora de las condiciones laborales y salariales; la estabilidad en el empleo; la contratación de un mayor número de personas para la ejecución del contrato; la formación y la protección de la salud y la seguridad en el trabajo; la aplicación de criterios éticos y de responsabilidad social a la prestación contractual, o los criterios referidos al suministro o a la utilización de productos basados en un comercio equitativo durante la ejecución del contrato» (art. 145.2.1. ${ }^{\circ}$ ). Sin duda, este tenor es mucho más amplio que el empleado por el anterior art. 150.1 TRLCSP, que se refería únicamente a «la satisfacción de exigencias sociales que respondan a necesidades, definidas en las especificaciones del contrato, propias de las categorías de población especialmente desfavorecidas a las que pertenezcan los usuarios o beneficiarios de las prestaciones a contratar».

Aun cuando el paso ha sido de gigante, la nueva regulación se queda corta, teniendo en cuenta que el Programa Nacional de Reformas de 2014 proponía que la adjudicación recayera siempre «en la oferta económica y social más ventajosa».

\section{La exclusión de ofertas anormalmente bajas. La apuesta por el cumplimiento de los convenios sectoriales en cuanto a condiciones salariales se refiere}

La preocupación porque en las obras o servicios encomendados por la Administración a empresarios privados se respete la normativa laboral y se ofrezcan condiciones de trabajo aceptables para los trabajadores ocupados en ellos ha sido acogida por la Organización Internacional del Trabajo (OIT), en especial en el importante Convenio sobre las cláusulas de trabajo (contratos celebrados por las autoridades públicas) de 1949 (núm. 94), acompañado de la Recomedación núm. 84 de la misma 
denominación y el mismo año. Para lograr tal objetivo, este Convenio utiliza una técnica jurídica peculiar: en lugar de imponer la obligación de los Estados de establecer en su legislación que los contratistas reconozcan a sus trabajadores salarios y condiciones de trabajo no menos favorables a las del lugar y actividad en cuestión, prevé que la legislación nacional obligue a las Administraciones Públicas a incorporar en los contratos administrativos las denominadas «cláusulas de trabajo», en virtud de las cuales los contratistas deben comprometerse a reconocer a sus trabajadores salarios, horarios y condiciones de empleo no menos favorables que las establecidas en convenio colectivo, laudo o normativa estatal para un trabajo de igual naturaleza en la misma actividad y en la región donde se ejecute el contrato. Este sistema tiene la ventaja de crear una responsabilidad contractual específica frente a la Administración, garantizada incluso con la posible resolución del contrato, pero tiene el inconveniente de dejar esa obligación a los avatares de la lógica competitiva, factor de debilidad que el tiempo ha acentuado en los sistemas continentales de contratación ${ }^{41}$.

No cabe pasar por alto, como elemento agravante adicional, la existencia de un severo peligro que la contratación pública conlleva desde el punto de vista laboral, pues el principio de riesgo y ventura que asume el contratista o el concesionario le animará, como es obvio, a reducir todas aquellas partidas económicas que sea posible con el objetivo de aumentar el lógico beneficio empresarial que preside su actividad, lo cual tendrá una repercusión directa (negativa) en cuanto a las condiciones de trabajo. Es más, la rebaja de los precios de los contratos públicos que conlleva la externalización de las actividades públicas en los momentos actuales de restricciones presupuestarias va a afectar igualmente in peius sobre las condiciones laborales de los trabajadores, que se ven perjudicadas sobre todo en la vertiente salarial, pero también en otros aspectos como una mayor inestabilidad en el empleo, un importante incremento de la carga de trabajo o una definición más polivalente de las funciones a realizar.

Merece una valoración positiva, por tanto, que la Ley 9/2017 introduzca una regulación más estricta en cuanto al rechazo de las ofertas anormalmente bajas, pues el art. 149.4 deja claro que, en todo caso, «los órganos de contratación rechazarán aquellas propuestas que no cumplen las obligaciones aplicables en materia [...] social o laboral, nacional o internacio-

${ }^{41}$ M. Rodríguez-PiÑERO y BRAVo-FerRER, «La contratación administrativa y el Derecho del Trabajo», Relaciones Laborales, núm. 11 (2005), pp. 5 y ss. 
nal, incluyendo el incumplimiento de los convenios colectivos sectoriales vigentes, en aplicación de lo establecido en el art. 201». Sin embargo, no se entiende por qué, marginando otro tipo de normas internacionales, el art. 201 remite a un listado tasado de convenios de la OIT, como son los siguientes: núm. 87, sobre la libertad sindical y la protección del derecho de sindicación; núm. 98, sobre el derecho de sindicación y de negociación colectiva; núm. 29, sobre el trabajo forzoso; núm. 105, sobre la abolición del trabajo forzoso; núm. 138, sobre la edad mínima; núm. 111, sobre la discriminación (empleo y ocupación); núm. 100, sobre igualdad de remuneración, o núm. 182, sobre las peores formas de trabajo infantil.

Asimismo, sorprende la referencia expresa al incumplimiento del convenio colectivo sectorial, alterando el sistema de fuentes establecido en el Real Decreto Legislativo 2/2015, de 23 de octubre, por el que se aprueba el texto refundido de la Ley del Estatuto de los Trabajadores (ET), en virtud del cual en determinadas materias el convenio colectivo de empresa tiene prioridad aplicativa sobre el sectorial, a saber: a) La cuantía del salario base y de los complementos salariales, incluidos los vinculados a la situación y resultados de la empresa. b) El abono o la compensación de las horas extraordinarias y la retribución específica del trabajo a turnos. c) El horario y la distribución del tiempo de trabajo, el régimen de trabajo a turnos y la planificación anual de las vacaciones. d) La adaptación al ámbito de la empresa del sistema de clasificación profesional de los trabajadores. e) La adaptación de los aspectos de las modalidades de contratación que se atribuyen por esta ley a los convenios de empresa. $f$ ) Las medidas para favorecer la conciliación entre la vida laboral, familiar y personal. $g$ ) Aquellas otras que dispongan los acuerdos y convenios colectivos a que se refiere el art. 83.2 (art. 84.2 ET) ${ }^{42}$.

Merece, no obstante, una valoración muy positiva la mención explícita de tales convenios sectoriales y, por tanto, su obligatorio respeto con independencia de la existencia de un convenio de empresa, pues en muchas ocasiones los convenios de empresa se han hecho para, tras un descuelgue, reducir de manera importante las condiciones laborales esenciales de los trabajadores, principalmente las salariales. Con esta previsión parece que se termina con las dudas que planteaba, en paradigmático ejemplo, la incorporación de previsiones garantistas de este tipo en algunas disposicio-

${ }^{42}$ T. Pérez del Río y M. Zambonino Pulito, «La acción positiva y sus instrumentos: la inclusión de las cláusulas sociales de género en la contratación de las Administraciones Públicas», Revista de Derecho Social, núm. 43 (2008), p. 52. 
nes forales en relación con contratos de obra, respecto de las cuales la Sala de lo Contencioso-Administrativo del Tribunal Supremo había considerado necesaria la intervención del legislador ${ }^{43}$. El paso dado por la LCSP ha sido importante en aras a garantizar la transparencia y a evitar la precarización de las condiciones laborales de los trabajadores privados que prestan servicios públicos, pero la lectura puede que no sea tan positiva si se tiene en cuenta que la exigencia de que el convenio sectorial esté «vigente» puede evitar su aplicación si ha sido desplazado, en las materias que prevé el art. 84.2 ET, por un convenio de empresa ${ }^{44}$.

\section{Presupuesto base de la licitación}

$\mathrm{Al}$ objeto de garantizar los salarios de los trabajadores contribuye también la exigencia de desglose en el presupuesto base de licitación (esto es, el límite máximo de gasto que en virtud del contrato puede comprometer el órgano de contratación), indicando en el pliego de cláusulas administrativas particulares o documento regulador de la licitación los costes directos e indirectos y otros eventuales gastos calculados para su determinación. En los contratos en los que el coste de los salarios de las personas empleadas para su ejecución forme parte del precio total del contrato, el presupuesto base de licitación indicará de forma desglosada y con desagregación de género y categoría profesional los costes salariales estimados a partir del convenio laboral de referencia (art. 100 LCSP). Asimismo, «en el cálculo del valor estimado de los contratos deberá tenerse en cuenta, como mínimo, además de los costes derivados de la aplicación de las normativas laborales vigentes, otros costes que se deriven de la ejecución material de los servicios, los gastos generales de estructura y el beneficio industrial [...] En los contratos de servicios y de concesión de servicios en los que sea relevante la mano de obra, en aplicación de la normativa laboral vigente a que se refiere el párrafo anterior, se tendrán especialmente en cuenta los costes laborales derivados de los convenios colectivos sectoriales de aplicación»

${ }^{43}$ SSTS (Cont.-Admtivo.) de 23 de mayo, 31 de mayo y 2 de junio 2016 (recs. 1383/2015, 1242/2016 y 852/2015). Vid. también E. LarRazabal AstigarRaga, «La introducción del salario mínimo en la contratación pública: análisis jurisprudencial del TJUE y del TSJPV», Revista de Derecho Social, núm. 71 (2015), pp. 125 y ss., e íD., «La jurisprudencia del Tribunal Supremo sobre la posibilidad de exigir la aplicación del convenio colectivo del lugar de ejecución en la contratación pública», Lan Harremanak, núm. 1 (2017), pp. 138 y ss.

${ }^{44}$ M. R. VAlLeCillo GÁmEZ, «Aspectos sociolaborales de la nueva Ley de Contratos del Sector Público...», op. cit., pp. 188-190. 
(art. 101 LCSP). Igualmente, la previsión que sienta que «en aquellos servicios en los que el coste económico principal sean los costes laborales deberán considerarse los términos económicos de los convenios colectivos sectoriales, nacionales, autonómicos y provinciales aplicables en el lugar de prestación de los servicios» (art. 102.3) ${ }^{45}$.

\section{Utilización de criterios de desempate de contenido social a la hora de adjudicar el contrato. Claras medidas de fomento del empleo «selectivo»}

El art. 147 LCSP introduce, ahora en el propio texto articulado de la Ley, pues con anterioridad se ubicaba dentro de las disposiciones adicionales, una habilitación o autorización a los órganos de contratación de las Administraciones Públicas para señalar en los pliegos de cláusulas administrativas particulares la preferencia en la adjudicación de los contratos (con exclusión del resto de los concurrentes al proceso de selección de contratistas) en los supuestos de empate a favor de aquellas proposiciones presentadas por determinados empleadores que reúnan unas cualidades subjetivas determinadas, postulado admitido sin problemas por las instancias europeas ${ }^{46}$ tal y como anteriormente se explicó.

Tratándose de establecer criterios específicos para dirimir la paridad entre las ofertas más meritorias, una vez realizada la valoración correspondiente, el precepto mencionado exige además que dichos criterios sean debidamente publicitados y estén vinculados al objeto del contrato, que la documentación acreditativa sea aportada en el momento en que se produzca el empate - y no con carácter previo- y que los licitadores se refieran a los grupos siguientes ${ }^{47}$ :

${ }^{45}$ Sobre la posibilidad de introducir previsiones de esta naturaleza en los pliegos vid. J. I. MARCos GonZÁlez, «Cláusulas sociales en los contratos del sector público: ¿una opción legal de corrección de la reforma laboral? Comentario a la Sentencia del Tribunal Superior de Justicia del País Vasco, Sala de lo Contencioso-Administrativo, de 30 de diciembre de 2014, rec. núm. 643/2013», Revista de Trabajo y Seguridad Social (Centro de Estudios Financieros), núm. 387 (2015), pp. 108 y ss.

46 S. Rodríguez EsCANCIANO, «La vis expansiva de las cláusulas sociales en el sistema de contratación pública: un cauce para el fomento del empleo de los colectivos más desfavorecidos permitido por el Derecho comunitario», en AAVV, Los mercados laborales y las políticas sociales en Europa. XX Congreso Nacional de Derecho del Trabajo y de la Seguridad Social, vol. II, Madrid, Ministerio de Trabajo y Seguridad Social, 2010, pp. 749 y ss.

${ }^{47}$ C. SÁez LaRA, «Las cláusulas sociales en los contratos del sector público», Relaciones Laborales, núm. 2 (2009), p. 520. 


\section{A) Empresas que den ocupación a trabajadores discapacitados}

La primera preferencia se refiere a las proposiciones presentadas por aquellas empresas que, al vencimiento del plazo de presentación de ofertas, tengan en su plantilla un porcentaje de trabajadores con discapacidad superior al que les imponga la normativa ${ }^{48}$. En este supuesto, si varias empresas licitadoras de las que hubieren empatado en cuanto a la proposición más ventajosa acreditan tener relación laboral con personas con discapacidad en un porcentaje superior al indicado, tendrá preferencia en la adjudicación del contrato el licitador que disponga del mayor número de trabajadores fijos con discapacidad en su plantilla, apostando, pues, por el principio de estabilidad en el empleo, pero sin mencionar que se trate de contrataciones a jornada completa.

Con esta previsión se pretende contribuir a doblegar una voluntad empresarial poco proclive a contratar a quien no asegura un rendimiento laboral óptimo. Se trata de una medida de «empleo selectivo» que pretende favorecer, en último extremo, a los propios discapacitados, haciendo gala de lo que se ha dado en llamar discriminación positiva, cuya plena constitucionalidad ha sido reconocida por el máximo intérprete de la Norma Fundamental ${ }^{49}$. Es más, la inexigencia de un volumen mínimo de trabajadores sobre el cual aplicar el referido porcentaje conlleva, como lógica consecuencia (beneficiosa a todas luces), que las pequeñas empresas, mayoritarias en nuestro entorno empresarial y fuentes destacadas de la creación de empleo, también puedan contribuir a la inserción del colectivo de discapacitados. Ahora bien, no se precisa el grado de disfuncionalidad exigido para entender cumplido el porcentaje de reserva, razón por la cual se verán favorecidos los sujetos menos disminuidos (es decir, los que superen en poco el porcentaje de reducción del 33 por 100), ya que las empresas suelen «hacer una criba» y contratan a los trabajadores cuya discapacidad es menos acusada. Para superar esta situación procede efectuar la siguiente propuesta de lege ferenda: valorar más a los traba-

48 Puede traerse a colación la Resolución del Tribunal Administrativo Central de Recursos Contractuales 1023/2016, de 9 de diciembre, que entiende adecuada la adjudicación del contrato, en aplicación del criterio de desempate supra enunciado interpretado analógicamente, a aquella empresa que mayor porcentaje de trabajadores con discapacidad tenga en su plantilla, aunque fuera inferior al mínimo legal del 2 por 100, cuando ninguna de las dos licitadoras que han obtenido más puntuación alcanza ese parámetro.

49 Por todas, STCo 269/1994, de 9 de octubre. 
Susana Rodríguez Escanciano La apuesta por la mejora de las condiciones laborales...

jadores con discapacidades más severas (personas con una afectación psíquica, sobre todo $)^{50}$.

\section{B) Empresas de inserción}

La segunda preferencia se refiere a proposiciones de empresas de inserción que cumplan con los requisitos establecidos en su normativa reguladora para tener esta consideración. El fin último de estas entidades es el fomento del empleo de los excluidos sociales, no en vano el art. 3 de la Ley 40/2007 dispone que, al objeto de conseguir la integración que se proponen, deben diseñar, para cada trabajador, un itinerario que persigue suplir las carencias y alcanzar los aprendizajes necesarios para lograr el suficiente grado de empleabilidad que permita su posterior acceso al mercado de trabajo ordinario. Dicho itinerario se caracteriza por las notas de voluntariedad (la decisión de seguirlo corresponde al propio afectado), singularidad (se elabora para cada individuo en concreto, teniendo en cuenta sus características y circunstancias) y personalización (con seguimiento particularizado por un tutor según un plan flexible previamente acordado) ${ }^{51}$.

\section{C) Entidades sin ánimo de lucro}

La tercera mención del art. 147 va referida, en la adjudicación de los contratos relativos a prestaciones de carácter social o asistencial, a las proposiciones presentadas por entidades sin ánimo de lucro, con personalidad jurídica, siempre que su finalidad o actividad tenga relación directa con el objeto del contrato, según resulte de sus respectivos estatutos o reglas fundacionales, y figuren inscritas en el correspondiente registro oficial.

Se trata de potenciar el denominado tercer sector, lo cual va a repercutir lógicamente en el recurso al voluntariado tan abundante en este ámbito, pero también en el fomento del empleo de escasa cualificación, tal y como sucedería con desempleados expulsados del mercado laboral como con-

${ }^{50}$ D. Martínez Fons, Cláusulas sociales, libre competencia y contratación pública, documento de trabajo 153 (2009), p. 22, disponible en bttp://www.fundacionalternativas.org/ public/storage/laboratorio_documentos_archivos/f04408dde31c25ad9d03a44a1cddb9f6.pdf.

51 Por extenso vid. R. Aguilera IzQuierdo, El régimen jurídico de las empresas de inserción, Madrid, Civitas, 2009. 
secuencia de la introducción de las tecnologías de la información o de la entrada en recesión de ciertos sectores tradicionales como la construcción, de jóvenes y en un alto grado también de mujeres ${ }^{52}$. Precisamente, pues, alguno de los colectivos más necesitados.

Las entidades sin ánimo de lucro respecto de las cuales es predicable la preferencia en la adjudicación deben venir revestidas, además, de personalidad jurídica y dotadas de una determinada organización; tal exigencia ha de quedar cumplida por cualesquiera de las formas de personificación previstas en el ordenamiento jurídico, constituyendo, además, su inscripción en el registro una exigencia también esencial para la obtención de la prebenda establecida en la LCSP. Además, el patrimonio de la entidad sin ánimo de lucro ha de hallarse destinado a la realización de fines de interés general, lo cual viene a suponer en la práctica su intervención como coadyuvantes de las Administraciones Públicas, no en vano estas entidades, como personas jurídico-privadas que son, no tienen la consideración de poderes administrativos, en cuanto no están dotadas de imperium o soberanía, pero en tanto en cuanto es precisamente a las organizaciones públicas a quienes se impone como obligación el logro del interés general, la intervención de las entidades sin ánimo de lucro en este campo a través del sistema de contratación administrativa va a quedar limitado a colaborar en la satisfacción pública de las demandas sociales referidas fundamentalmente a aquellos aspectos relacionados con los derechos de tercera generación o fundados en la solidaridad (paz, protección del medio ambiente, desarrollo, servicios sociales, culturales o de ocio). De todas formas, es necesario distinguir el fin, que necesariamente tiene que ser general, y la realización de dicha finalidad, pues al concertarse, in casu, con determinadas entidades no lucrativas, siempre acabará beneficiando en último término a personas determinadas. Es más, para la aplicación de la preferencia en la adjudicación es necesario también que los fines de la entidad tengan relación directa con el objeto del contrato. Tomando en consideración que en este caso dicha prioridad sólo es aplicable a los vínculos contractuales relativos a prestaciones de carácter social o asistencial, resulta que los fines de estos sujetos han de tener, además de relación con el objeto del contrato, de nuevo, carácter social o asistencial ${ }^{53}$.

52 D. MarTínez Fons, «La contratación pública como instrumento de la política de empleo y la libre competencia», en AAVV, Los mercados laborales y las politicas sociales en Europa. XX Congreso Nacional de Derecho del Trabajo y de la Seguridad Social, vol. II, Madrid, Ministerio de Trabajo y Seguridad Social, 2010, pp. 649 y ss.

53 J. J. TORRES FERNÁNDEZ, «La Administración contratante y contratistas de las Administraciones Públicas», Revista Española de Control Externo, vol. 4, núm. 11 (2002), pp. 85 y ss. 


\section{D) Organizaciones de comercio justo}

También tienen preferencia las ofertas de entidades reconocidas como Organizaciones de Comercio Justo para la adjudicación de los contratos que tengan como objeto productos en los que exista alternativa de comercio justo. La puesta en práctica de esta preferencia puede suponer un acicate importante a la hora de conseguir que las empresas muestren una mayor implicación frente a todas las formas aún subsistentes de explotación laboral, no en vano el comercio justo tiene como finalidad principal la de ofrecer, vender y promocionar productos que cumplen determinados criterios sociales y de desarrollo, contribuyendo a la erradicación de la pobreza a través de la promoción de oportunidades de evolución a pequeños productores y trabajadores de los países más desfavorecidos (Resolución del Parlamento Europeo sobre comercio justo y desarrollo) ${ }^{54}$.

Aun cuando se han dado pocos pasos en este sentido, cabe señalar algunas experiencias municipales de concursos públicos para el suministro de productos alimenticios (sobre todo café, como ha sucedido en el Ayuntamiento de Barcelona y en la Universidad Autónoma de esta misma localidad) y productos textiles en base a criterios sociales, éticos y solidarios, exigiendo en algunos casos contar con la certificación FLO (Fairtrade Labelling Organizations), una etiqueta que ya figura en los productos que se venden en países como Holanda, Francia, Reino Unido, Alemania o Canadá y garantiza que un artículo ha sido elaborado en condiciones de trabajo dignas para sus empleados.

Con esta previsión se pretende conseguir una doble finalidad: que las Administraciones Públicas incorporen en relación con su cadena de proveedores la estrategia derivada del comercio justo y, a la vez y con ello, incidir en el plano de la subcontratación internacional, garantizando que la empresa contratista que suministra el producto de que se trate respete en origen —normalmente países subdesarrollados— los estándares mínimos derivados de dicho comercio justo.

54 C. Gala DurÁn, «Responsabilidad social empresarial, derecho a la libre prestación de servicios y contratación pública de obras o servicios», Relaciones Laborales, núm. 13 (2010), p. 18. 


\section{E) Empresas que promueven el principio de igualdad de trato entre mujeres y hombres}

También tienen preferencia las proposiciones presentadas por las empresas que, al vencimiento del plazo de presentación de ofertas, incluyan medidas de carácter social y laboral que favorezcan la igualdad de oportunidades entre mujeres y hombres. Esta disposición, que no es sino una reiteración de lo previsto en el art. 34.2 LOIEMH, obliga a interrogarse sobre los cauces reales y las manifestaciones concretas a través de los cuales el Ente público podrá comprobar que efectivamente la posible empresa adjudicataria promueve realmente la demandada igualdad efectiva. Alguna pista ofrece a este efecto el mencionado art. 71.1.d) LCSP y, cómo no, el propio articulado de la LOIEMH ${ }^{55}$ :

1. Esta Ley contempla la creación de un distintivo para reconocer a aquellas empresas que destaquen por la aplicación de políticas de igualdad de trato y de oportunidades con sus trabajadores y trabajadoras, que podrá ser utilizado como señuelo en el tráfico comercial de la entidad productiva. Con el fin de obtener este emblema, cualquier organización empresarial podrá presentar al Ministerio de Empleo un balance sobre los parámetros de igualdad implantados respecto de las relaciones de trabajo y la publicidad de los productos y servicios prestados (art. 50 LOIEMH). Para la concesión del mismo se tendrán en cuenta, entre otros criterios, la presencia equilibrada de mujeres y hombres en los órganos de dirección y en los distintos grupos y categorías profesionales de la empresa, la adopción de planes de igualdad u otras medidas innovadoras de fomento de la paridad, así como la publicidad no sexista de los productos o servicios de la entidad empresarial (art. 46 LOIEMH). Sin duda, la posesión de tal distintivo puede ser considerada por la Administración como acreditación empresarial para aplicar el criterio social de desempate.

2. La LOIEMH invita a las sociedades obligadas a presentar cuenta de pérdidas y ganancias no abreviada a procurar incluir en su consejo de administración, en los nombramientos que se vayan produciendo a medida que venza el mandato de los actuales consejeros, un número de muje-

55 R. CABAlLERo SÁnChez, «La integración del principio de igualdad en las distintas políticas públicas sectoriales», en A. MonToya Melgar (dir.), Igualdad de mujeres y bombres (comentario a la Ley Orgánica 3/2007, de 22 de marzo, para la igualdad efectiva entre mujeres y hombres), Madrid, Civitas, 2007, p. 241. 
res que permita alcanzar una presencia equilibrada entre ambos sexos en un plazo de ocho años (art. 75). La mayor o menor diligencia en el cumplimiento de tal previsión por parte de la empresa puede suponer también un claro indicio en su favor a la hora de licitar.

3. La Ley 3/2007 incorpora un nuevo mandato en el art. 85.1 ET de conformidad con el cual, y «sin perjuicio de la libertad de las partes para determinar el contenido de los convenios colectivos, en la negociación de los mismos existirá, en todo caso, el deber de negociar medidas dirigidas a promover la igualdad de trato y de oportunidades entre mujeres y hombres en el ámbito laboral o, en su caso, planes de igualdad». Así pues, las alternativas son dos: o se negocia un plan de igualdad o se negocian «medidas dirigidas a promover la igualdad de trato y de oportunidades entre mujeres y hombres en el ámbito laboral», existiendo en este sentido un deber de negociar que, para ser constitucional, debe ser respetuoso con la libertad de las partes a la hora de «determinar el contenido de los convenios colectivos», por lo que no habrá obligación de llegar a un acuerdo en ninguno de los dos sentidos, pero sí un deber inexcusable de negociar de buena fe sobre estas cuestiones ${ }^{56}$.

La importancia de los planes de igualdad no debe ser minusvalorada; no en vano a través de los mismos se canalizará el conjunto de medidas de acceso al empleo, clasificación y promoción profesional, formación, retribuciones y ordenación del tiempo de trabajo, tendentes a alcanzar en la organización productiva, después de realizar un diagnóstico de situación, la igualdad entre mujeres y hombres y a eliminar las discriminaciones por razón de sexo (art. 45 LOIEMH). Los planes de igualdad tendrán, además, tres partes: 1) la fijación de los objetivos a alcanzar; 2) la estrategia y prácticas a adoptar para su consecución; 3) el establecimiento de sistemas eficaces de seguimiento y evaluación de los objetivos fijados (art. 46.1 LOIEMH) ${ }^{57}$. Es más, la propia LOIEMH se encarga de precisar el procedimiento para la articulación de este deber de negociar planes de igualdad (que no el deber de llegar a un acuerdo, como ya consta) en las empresas de más de 250 trabajadores: «En los convenios colectivos de ámbito empresarial, el deber de negociar se formalizará en el marco de la negociación de dichos convenios; en los convenios de ámbito superior a

56 A. Pedrajas Moreno y T. Sala Franco, «Ley Orgánica 3/2007, de 22 de marzo, para la igualdad efectiva de mujeres y hombres. Comentario de urgencia de sus aspectos laborales y de Seguridad Social», Tirant on Line, núm. 1044019, p. 8.

57 R. EsCudERo Rodríguez, «Planes de igualdad en la Ley Orgánica 3/2007, de igualdad efectiva entre mujeres y hombres», Relaciones Laborales, núm. 9 (2007), pp. 61 y ss. 
la empresa, el deber de negociar se formalizará a través de la negociación colectiva que se desarrolle en la empresa en los términos y condiciones que se hubieran establecido en los indicados convenios para cumplimentar dicho deber de negociar a través de las oportunas reglas de complementariedad» (art. 85.2 ET) ${ }^{58}$.

Como no podía ser de otra manera, la LOIEMH amplía las competencias de los comités de empresa, modificando el art. 64.1 ET con el fin de atribuirles «el derecho a recibir información, al menos anualmente, relativa a la aplicación en la empresa del derecho de igualdad de trato y de oportunidades entre mujeres y hombres, entre los que se incluirán datos sobre la proporción de unas y otros en los diferentes niveles profesionales, así como, en su caso, sobre las medidas que se hubieran adoptado para fomentar la igualdad entre mujeres y hombres en la empresa y, de haberse establecido un plan de igualdad, sobre el mismo» (art. 64.1 ET); el derecho de «vigilancia del respeto y aplicación del principio de igualdad de trato y de oportunidades entre mujeres y hombres» [art. 64.1.9.c) ET], y el derecho a «colaborar con la dirección de la empresa en el establecimiento y puesta en marcha de las medidas de conciliación» (art. 64.1.13 ET) ${ }^{59}$. Todas estas prerrogativas serán, como fácilmente puede imaginarse, muy útiles.

4. Teniendo en cuenta que son las mujeres las que han tenido históricamente $-\mathrm{y}$ siguen teniendo- una mayor dificultad para hacer compatible la dedicación a un trabajo por cuenta propia o ajena con la necesaria atención a sus propias necesidades e inquietudes personales y con la plena participación en la vida familiar en condiciones de igualdad con el resto de sus componentes, es importante que la Administración valore la sensibilidad de las empresas en materia de conciliación a través de diversos indicios que pueden recogerse en las memorias de responsabilidad social corporativa, como pueden ser, entre otros, el aumento y mejora de los contenidos normativos en materia de permisos, descansos, reducciones y excedencias previstos a nivel legal para el cuidado de hijos y la atención de familiares, permitiendo una mayor flexibilidad laboral de los trabajadores; la adopción de fórmulas de trabajo a tiempo parcial o de trabajo a distancia; el diseño de cauces para evitar, en la medida de lo posible, los viajes y desplazamientos de los trabajadores con ocasión de su desempeño pro-

58 J. LuJÁn AlCARAZ, «La igualdad en la responsabilidad social de las empresas», Aranzadi Social, núm. 12 (2007), p. 22.

${ }_{59}$ M. C. JuAN GÓMEZ, «Breves apuntes sobre discriminación positiva por razón de género y contratación pública», Diario La Ley, núm. 8978 (2017), p. 5. 
fesional (carga gravosa que dificulta sobremanera la organización familiar), favoreciendo otras formas de relación menos agresivas de la indemnidad familiar, como puede ser la utilización de videoconferencias para celebrar a distancia cuantas reuniones de trabajo fueran necesarias, o la articulación de ventajas y beneficios sociales concretos destinados a facilitar a las trabajadoras, desde distintos puntos de vista, la atención que pueden dispensar a su familia, destacando sobre todo las guarderías incorporadas al propio centro de trabajo u otro tipo de auxilios económicos destinados a sufragar determinados gastos de los hijos (estudios, enfermedades, discapacidades... ${ }^{60}$.

El cumplimiento escrupuloso de todas estas previsiones por una determinada empresa puede servir, igualmente, como pauta a tener en cuenta por la Administración para el desempate en la licitación, no en vano la consecución de la deseada paridad entre sexos en las relaciones laborales no es sólo un derecho fundamental de la mujer ni sólo un valor superior del ordenamiento, es también un requisito y exigencia para lograr una sociedad más justa y una economía más dinámica y competitiva. Al final - y a través de la preferencia en la adjudicación de los contratos públicos a favor de las empresas especialmente sensibles en materia de igualdad laboral por razón de género-, el empleo de las mujeres quedará favorecido ${ }^{61}$.

\section{F) Preferencias supletorias}

Para evitar que posibles lagunas en los pliegos dejen sin efecto este tipo de prioridades en caso de equiparación entre las ofertas más ventajosas, el art. 147.2 LCSP establece una regulación específica de desempate, referida también al momento de finalizar el plazo de presentación de ofertas: a) mayor porcentaje de trabajadores con discapacidad o en situación de exclusión social en la plantilla de cada una de las empresas, primando, en caso de igualdad, el mayor número de trabajadores fijos con discapacidad en plantilla o el mayor número de personas trabajadoras en inclusión en la plantilla; b) menor porcentaje de contratos temporales en la planti-

${ }^{60}$ R. TASCÓN LÓPEZ, «La responsabilidad social empresarial y la igualdad», en S. RODRíguez Escanciano y M. R. Martínez Barroso (dirs.), Propuestas para la igualdad de género en los procesos de negociación colectiva, Pamplona, Aranzadi, 2016, pp. 152 y ss.

${ }^{61}$ S. Lesmes Zabalegui, «Contratación pública y discriminación positiva. Cláusulas sociales para promover la igualdad de oportunidades entre mujeres y hombres en el mercado laboral», Lan Harremanak, núm. 13 (2005), p. 70. 
lla de cada una de las empresas; c) mayor porcentaje de mujeres empleadas en la plantilla de cada una de las empresas; $d$ ) el sorteo, en caso de que la aplicación de los anteriores criterios no hubiera dado lugar a desempate.

De todas formas, es difícil que, en un proceso de valoración de ofertas en el que existe un detallado baremo con puntuaciones decimales, tenga lugar una equivalencia entre distintas propuestas más ventajosas, de ahí que estas preferencias no vayan a tener demasiada trascendencia práctica.

\section{CONDICIONES ESPECIALES DE EJECUCIÓN}

La posibilidad de supeditar las adjudicaciones de los contratos públicos a la colaboración del adjudicatario en determinadas políticas sociales se muestra ya con claridad en el Libro Verde de la Contratación Pública de la Unión Europea, el cual en su apartado 5.42 establece la imposición, como condición de ejecución de los contratos administrativos adjudicados, del respeto de las obligaciones de carácter social encaminadas, por ejemplo, a fomentar el empleo de las mujeres o a favorecer la protección de determinadas categorías desfavorecidas. La respuesta común formulada por la Comisión Europea a las preguntas escritas E-0816/00 y E-0817/00 62 se manifiesta, igualmente, a favor de «plantear, como condición de ejecución de contratos públicos ya adjudicados, el respeto de obligaciones de carácter social [...] (pues ello no supone sino) un compromiso de los licitadores para adoptar determinadas medidas si se les adjudica el vínculo contractual». También la Comunicación Interpretativa de 15 de octubre de 2001 determina con claridad que: «Es ante todo en la fase de ejecución, es decir, una vez adjudicado, cuando un contrato público puede constituir para los poderes adjudicadores un medio de fomentar la persecución de objetivos sociales ${ }^{63}$. En efecto, éstos pueden imponer al titular del contrato la observancia de cláusulas contractuales relativas a la forma de ejecución del mismo que sean compatibles con el Derecho comunitario. Estas cláusulas pueden englobar medidas laborales a favor de determinadas categorías de personas y actuaciones positivas en materia de empleo ${ }^{64}$.

${ }^{62}$ DOCE, num. C-374E, de 28 de diciembre de 2000.

$63 \mathrm{~J}$. A. PÉrez-Illzarbe, «Las cláusulas sociales en la reforma de la legislación de contratos del sector público», Zerbitzuan, núm. 40 (2006), p. 29.

${ }^{64}$ E. VÁzQuez LaCUNZA, «El pago de un salario mínimo como condición especial de ejecución en los contratos públicos», Contratación Administrativa Práctica, núm. 146 (2016), pp. 28 y ss. 


\section{La colaboración de los adjudicatarios con determinados estándares sociales}

Con las posibilidades que marca la Directiva 2014/24, el art. 35.1.n) incluye entre las previsiones expresas que debe incluir el documento en que se formalice el vínculo público correspondiente, una vez adjudicado, la relativa a «la obligación de la empresa contratista de cumplir durante todo el periodo de ejecución del contrato las normas y condiciones fijadas en el convenio de aplicación». En una primera aproximación se podría cuestionar la pertinencia u oportunidad de incorporar este apartado que no es sino un recordatorio de una obligación que ya recae sobre el empresario contratista en virtud del ordenamiento jurídico laboral vigente y que debiera resultar indisponible para las partes al formalizar el contrato administrativo, si bien no debe soslayarse la importante seguridad jurídica que incorpora para los trabajadores de las empresas adjudicatarias.

Por su parte, el art. 202 LCSP establece, al igual que su precedente, la posibilidad de que los órganos de contratación establezcan condiciones especiales en relación con la ejecución del contrato, siempre que estén vinculadas al objeto del contrato, no sean directa o indirectamente discriminatorias, sean compatibles con el Derecho comunitario y se indiquen en el anuncio de licitación y en los pliegos ${ }^{65}$.

Esta exigencia de vinculación al objeto de contrato no estaba prevista en el anterior art. 118 TRLCSP ${ }^{66}$, añadiendo un condicionante que limi-

${ }^{65}$ El Informe 16/2014 de la Junta Consultiva de Contratación Administrativa de Aragón ha llegado a la conclusión de que «la inclusión en los pliegos de cláusulas administrativas particulares de una condición especial de ejecución en virtud de la cual se obligue a las empresas adjudicatarias a no minorar las condiciones de trabajo (jornada, salario y mejoras sobre la legislación laboral básica) de los trabajadores adscritos al contrato en el que se incorpora la misma, en función del convenio colectivo que resulte de aplicación al presentarse la oferta, no vulnera el ordenamiento jurídico español ni el Derecho de la Unión Europea siempre que no sea discriminatoria y se respete el principio de publicidad». Sin embargo, la Resolución núm. 160/2016 del Tribunal Administrativo Central de Recursos Contractuales considera inadmisibles las siguientes condiciones especiales de ejecución por condicionar el poder de dirección del empresario: «Cualquier modificación sustancial de las condiciones de trabajo requerirá conformidad previa por parte del alcalde; en el caso de declaración judicial de despido improcedente, procede de forma forzosa la readmisión, salvo que el afectado optara por la indemnización, previa aprobación por el Pleno; para un mejor control de los trabajadores, la empresa adjudicataria intentará dentro de los posible la adscripción de los trabajadores en los ámbitos de las dependencias municipales y colegios».

${ }^{66}$ C. Gala Durán, «Responsabilidad social empresarial...», op. cit., p. 27. 
tará el juego de estas condiciones, pero que viene exigido por el considerando 98 de la Directiva 24/2014. A cambio, el actual art. 202 establece la obligación de incluir en el pliego de cláusulas administrativas particulares, al menos, una de las condiciones especiales de ejecución siguientes enunciadas en un listado abierto: «Hacer efectivos los derechos reconocidos en la Convención de las Naciones Unidas sobre los derechos de las personas con discapacidad; contratar un número de personas con discapacidad superior al que exige la legislación nacional; promover el empleo de personas con especiales dificultades de inserción en el mercado laboral, en particular de las personas con discapacidad o en situación o riesgo de exclusión social a través de empresas de inserción; eliminar las desigualdades entre el hombre y la mujer en dicho mercado, favoreciendo la aplicación de medidas que fomenten la igualdad entre mujeres y hombres en el trabajo; favorecer la mayor participación de la mujer en el mercado laboral y la conciliación del trabajo y la vida familiar; combatir el paro, en particular el juvenil, el que afecta a las mujeres y el de larga duración; favorecer la formación en el lugar de trabajo; garantizar la seguridad y la protección de la salud en el lugar de trabajo y el cumplimiento de los convenios colectivos sectoriales y territoriales aplicables; medidas para prevenir la siniestralidad laboral; otras finalidades que se establezcan con referencia a la estrategia coordinada para el empleo definida en el art. 145 del Tratado de Funcionamiento de la Unión Europea (potenciar una mano de obra cualificada, formada y adaptable y mercados laborales con capacidad de respuesta al cambio económico), o garantizar el respeto a los derechos laborales básicos a lo largo de la cadena de producción mediante la exigencia del cumplimiento de las Convenciones fundamentales de la Organización Internacional del Trabajo, incluidas aquellas consideraciones que busquen favorecer a los pequeños productores de países en desarrollo con los que se mantienen relaciones comerciales que les son favorables, tales como el pago de un precio mínimo y una prima a los productores o una mayor transparencia y trazabilidad de toda la cadena comercial».

Es menester recordar también que el art. 33 LOIEMH establece cómo las Administraciones Públicas, en el ámbito de sus respectivas competencias, a través de sus órganos de contratación y en relación con la ejecución de los contratos que celebren, «podrán establecer condiciones especiales con el fin de promover la igualdad entre mujeres y hombres en el mercado de trabajo, de acuerdo con lo establecido en la legislación de contratos del sector público». Cabría incluir, así, la adopción de cualesquiera de las medidas mencionadas en los arts. 43, 45, 48, 73 o 75 LOIEMH en clara referen- 
cia, respectivamente, a la promoción de la igualdad en la negociación colectiva, elaboración y aplicación de planes de igualdad, prevención del acoso sexual y por razón de género en el trabajo, acciones de responsabilidad social de las empresas en materia de paridad sexual y participación de las mujeres en los consejos de administración de las sociedades mercantiles. Es más, en relación con las condiciones tendentes a promover la igualdad efectiva entre mujeres y hombres en el mercado de trabajo, la LOIEMH establece que, anualmente, el Consejo de Ministros, a la vista de la evolución e impacto de las políticas de igualdad en el mercado laboral, determinará los contratos de la Administración General del Estado y de sus organismos públicos que obligatoriamente deberán incluirlas. Igualmente cabe recordar que la disposición adicional primera de la Ley 40/2007 también prevé que «las condiciones especiales de ejecución de los contratos podrán incluir consideraciones relativas a la situación de exclusión social de los trabajadores vinculados a la realización del contrato, de conformidad con lo dispuesto en la legislación de contratos del sector público».

\section{Consecuencias del incumplimiento}

La oferta de un licitador que no aceptara la obligación en cuestión no se ajustaría al pliego de condiciones y no podría, por tanto, ser seleccionada. Por esta misma razón, en caso de incumplimiento posterior de los requerimientos establecidos una vez otorgado el contrato, el órgano de contratación puede optar por resolver el vínculo o por imponer penalidades, según disponga el pliego, sin que quede garantizado, no obstante, que lo así recaudado se destine a compensar a aquellas empresas que no resulten adjudicatarias de la contrata; antes al contrario, cada Administración debe preocuparse de que así sea en el caso concreto, lo cual no es mucho decir, pues, en principio, se deja en manos de los poderes públicos la opción entre la resolución o la imposición de penalidades. De hecho, la doctrina del Consejo de Estado ${ }^{67}$ y del Tribunal Supremo ${ }^{68}$ revela una indudable tendencia al mantenimiento del negocio contractual, estimando con carácter general que ésta es la solución que mejor defiende los intereses públicos a los que los contratos sirven siempre, sin perjuicio de la imposición al contratista de las penalidades o sanciones que pudieran pro-

${ }_{67}$ Dictámenes 1191/1993, de 25 de noviembre, y 3811/1998, de 8 de octubre.
68 STS (Cont.-Admtivo.), 14 de diciembre de 2011 (RJ 1433). 
ceder y de la exigencia de la posible responsabilidad por los daños, a no ser que la condición incumplida se haya diseñado como un aspecto esencial y no como una mera obligación accesoria o complementaria ${ }^{69}$.

La cuestión principal queda, pues, situada en determinar las vías mediante las cuales puede la Administración verificar el efectivo incumplimiento por el empresario adjudicatario de sus compromisos sociales adquiridos como condiciones de ejecución. Sería necesario, por tanto, extremar el cuidado en garantizar que la organización productiva que ha obtenido el contrato administrativo quede sometida a la obligación de soportar auditorías sociales externas destinadas a acreditar el respeto a tales exigencias, información de la que luego se servirá la Administración para adoptar o no la decisión de mantener o extinguir los vínculos adquiridos. También sería interesante que el Ente público pudiera exigir el acceso directo a los centros de trabajo de sus adjudicatarios, para poder comprobar de primera mano (a través de técnicos en la materia) el respeto de los parámetros sociales recogidos en los pliegos, llegando incluso a reservarse la facultad de poder realizar entrevistas privadas a los trabajadores que allí presten servicios para que, libre y anónimamente —ajenos a todo tipo de presión-, puedan describir la situación laboral realmente existente.

Se trata, en todo caso, de un precepto aplicable, a tenor del art. 319.1 LCSP, a los efectos y extinción de los contratos celebrados también por los poderes adjudicadores no pertenecientes a la categoría de Administraciones Públicas, como excepción a la aplicación de las reglas de Derecho privado (fundaciones públicas, mutuas, entidades públicas empresariales, sociedades mercantiles públicas, fondos sin personalidad jurídica o entidades con personalidad jurídica propia que hayan sido creadas específicamente para satisfacer necesidades de interés general que no tengan carácter industrial o mercantil, siempre que uno o varios sujetos pertenecientes al sector público financien mayoritariamente su actividad, controlen su gestión o nombren a más de la mitad de los miembros de su órgano de administración, dirección o vigilancia, partidos políticos, organizaciones sindicales y empresariales, así como las fundaciones y asociaciones vinculadas a cualquiera de ellos siempre que se cumplan determinadas circunstancias, como que su financiación sea mayoritariamente pública, u otro tipo de asociaciones de carácter público).

${ }^{69}$ Dictamen del Consejo de Estado 119/2014, de 25 de marzo, en relación con un incumplimiento de las cláusulas de seguridad y salud que motivó justificadamente la extinción del vínculo. 
El art. 202.4 LCSP añade, como novedad, que todas las condiciones especiales de ejecución que formen parte del contrato serán exigidas igualmente a todos los subcontratistas que participen de la ejecución del mismo, exigencia que evitará la precarización de las condiciones de trabajo en las cadenas de subcontratación.

\section{Causas de resolución del contrato como garantía en el percibo de las retribuciones}

El nuevo art. 211 LCSP incluye una nueva causa de resolución del contrato en su apartado i) como es «el impago, durante la ejecución del contrato, de los salarios por parte del contratista a los trabajadores que estuvieran participando en la misma, o el incumplimiento de las condiciones establecidas en los convenios colectivos en vigor para estos trabajadores también durante la ejecución del contrato».

El art. 212 LCSP aclara que «la resolución del contrato se acordará por el órgano de contratación, de oficio o a instancia del contratista, en su caso, siguiendo el procedimiento que en las normas de desarrollo de esta Ley se establezca. No obstante lo anterior, la resolución del contrato por la causa a que se refiere la letra $i$ ) del art. 211.1 sólo se acordará, con carácter general, a instancia de los representantes de los trabajadores en la empresa contratista; excepto cuando los trabajadores afectados por el impago de salarios sean trabajadores en los que procediera la subrogación de conformidad con el art. 130 y el importe de los salarios adeudados por la empresa contratista supere el 5 por 100 del precio de adjudicación del contrato, en cuyo caso la resolución podrá ser acordada directamente por el órgano de contratación de oficio».

\section{CONCLUSIÓN}

La nueva LCSP apuesta con rotundidad por que la política de contratación pública no sólo esté orientada a la consecución de objetivos de transparencia y eficiencia económica, sino también al logro de metas sociales, entre las cuales ocupa un lugar muy destacado la de evitar la precarización de las condiciones laborales de los trabajadores privados involucrados en la prestación indirecta de servicios de interés general. Exige, así, la incorporación efectiva de condiciones sociales a lo largo de todo el proceso de contratación. 